\title{
Fostering Social Capital in a Learning Network: Laying the Groundwork for a Peer-Support Service
}

Citation for published version (APA):

Fetter, S., Sloep, P., \& Berlanga Flores, A. J. (2010). Fostering Social Capital in a Learning Network: Laying the Groundwork for a Peer-Support Service. International Journal of Learning Technology, 5(4), 388-400.

https://doi.org/10.1504/IJLT.2010.038774

DOI:

10.1504/IJLT.2010.038774

Document status and date:

Published: 01/01/2010

Document Version:

Peer reviewed version

Document license:

CC BY

Please check the document version of this publication:

- A submitted manuscript is the version of the article upon submission and before peer-review. There can be important differences between the submitted version and the official published version of record. People interested in the research are advised to contact the author for the final version of the publication, or visit the DOI to the publisher's website.

- The final author version and the galley proof are versions of the publication after peer review.

- The final published version features the final layout of the paper including the volume, issue and page numbers.

Link to publication

\section{General rights}

Copyright and moral rights for the publications made accessible in the public portal are retained by the authors and/or other copyright owners and it is a condition of accessing publications that users recognise and abide by the legal requirements associated with these rights.

- Users may download and print one copy of any publication from the public portal for the purpose of private study or research.

- You may not further distribute the material or use it for any profit-making activity or commercial gain

- You may freely distribute the URL identifying the publication in the public portal.

If the publication is distributed under the terms of Article 25fa of the Dutch Copyright Act, indicated by the "Taverne" license above, please follow below link for the End User Agreement:

https://www.ou.nl/taverne-agreement

Take down policy

If you believe that this document breaches copyright please contact us at:

pure-support@ou.nl

providing details and we will investigate your claim.

Downloaded from https://research.ou.nl/ on date: 26 Apr. 2023 


\title{
Fostering Social Capital in a Learning Network: Laying the Groundwork for a Peer-Support Service
}

\author{
Sibren Fetter, Adriana J. Berlanga, Peter Sloep \\ Centre for Learning Sciences and Technologies (CELSTEC) \\ Open University the Netherlands \\ sfe@ou.nl, abl@ou.nl, psl@ou.nl
}

\begin{abstract}
In online learning environments communities are desirable, or as is the case for a learning network, even essential. This raises the question of how to attain and sustain these communities. In this article we argue that this can be achieved by fostering the social capital of the learning network. It is argued that this can be achieved by (1) improving the relationship characteristics, (2) increasing the
\end{abstract} sense of belonging to the community, and (3) heightening the mutual support. It is hypothesized that these improvements can be achieved by using so called AdHoc Transient Groups (AHTGs). These groups are a means through which learners are brought together for a specific, learning-related goal ('ad-hoc') and for only a limited amount of time ('transience'). In order to deepen the concept of AHTGs a relevant theoretical background as well as requirements for peersupport service that utilizes Ad-Hoc Transient groups is provided. This is followed by an example on how the service can be implemented in an existing learning network (eTwinning). Finally conclusions are drawn and future research discussed.

Keywords: Online lifelong learning, Ad Hoc Transient Communities, Peer support, Social capital, Sense of belonging to the community, Social network structure, Learning Networks

Acknowledgment: We would like to thank Francis Brouns and Marlies BitterRijpkema for their insightful help and comments. The present work was carried out as part of the TENCompetence project, which is (partly) funded by the European Commission (IST-2004-02787) (http://www.tencompetence.org). 


\section{Introduction}

In online learning environments community formation is desirable because of its capability to enhance learning (e.g. Anderson, 2004; Johnson, 2001). Communities improve learning by providing a social structure that encourages learners to participate, but also by offering goals and motivations (Dede, 1989). Also, a community gives participants a sense of belonging, provides easy access to other participants and, prevents the feeling of isolation participants might experience (Anderson, 2004; Eggens, Van der Werf, \& Bosker, 2008; Wenger, 2004). Thus they reduce the chance of participants dropping out (Kester et al., 2006; McInnerney \& Roberts, 2004; Rovai, 2002). One of these learning environments where communities are important is a Learning Network (LN) (See figure 1). As described

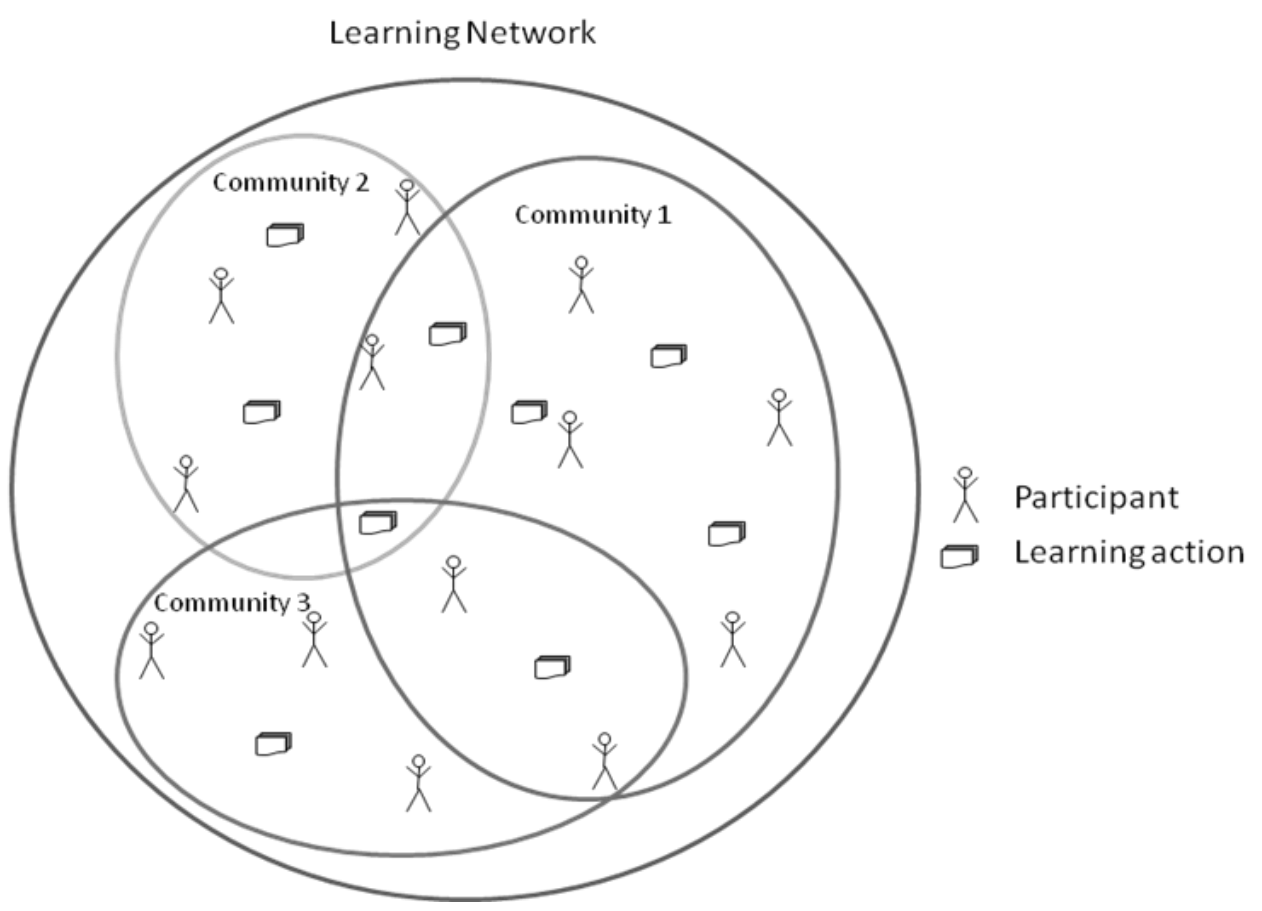

Figure 1 - A Learning Network

by Sloep (2008), a LN is a specific kind of online social network, one that is designed to facilitate lifelong learning and with a focus on non-formal learning (intentional learning, but without formal course). Figure 1 shows that a $L N$ consists of participants 
(who depending on the situation can have different roles such as: learner, tutor, professional, institution, etc.) and learning actions (e.g., learning materials, courses, blogs, etc.) all brought together through the use of computer technology (Berlanga et al., 2007; Koper, Rusman, \& Sloep, 2005). At the heart of each LN are the communities through which participants communicate with each other, collaborate and share information. Without communities, the $\mathrm{LN}$ would be an empty shell in which each learner works in isolation.

This dependency on communities brings forward an important problem for LNs, namely the unpredictability of online communities with respect to their emergence and sustainability (Arenas, Danon, Díaz-Guilera, Gleiser, \& Guimerá, 2004; Lock, 2002; A. Smith \& Kollock, 1999). While communities need to be internally dynamic in order to emerge and exist (Kester, et al., 2006), too little or too much of it can make them unstable. Instability has adverse effects such as low information flow or a high drop-out rate (Chang, Cheng, Deng, \& Chan, 2007; Jones, Ravid, \& Rafaeli, 2004). Therefore, it is important to increase the stability of LN communities. While many approaches are possible, we will focus on fostering social capital. The relationships between participants are a mayor dynamic in a social network. In turn, the social network structure is an integral part of social capital and depends on these relationships(Kadushin, 2004; Norris, Stevens, Pfefferbaum, Wyche, \& Pfefferbaum, 2007). Although there are many definitions for social capital, there is a growing consensus that "social capital stands for the ability of actors to secure benefits by virtue of membership in social networks or other social structures" (Portes, 1998, p. 6). In other words, social capital represents not just the relationships between participants, but also the actions using these relationships through which benefits are obtained. Therefore, we argue that to foster social capital 
in a $L N$, participants first of all need to be connected, which we refer to as (1) relationship characteristics (Coleman, 1990; Eggens, et al., 2008). Once participants are connected, they need to stay in the LN, which often depends on (2) participants' sense of belonging to a community (Hughey, Speer, \& Peterson, 1999; Krebs \& Holley, 2006; Pooley, Cohen, \& Pike, 2005; Rovai, 2002). Finally, the social capital of the LN can only flourish when the participants actually use their relationships (Portes, 1998) through actions like (3) mutual support between participants (Kester et al., 2007).

In a LN, therefore, these three pillars should be established and maintained over time. To this end, we argue that the use of peer-support is a promising means. Through peer-support, participants help each other and it is a well documented way of working within a learning setting. Moreover, peer-support not just benefits the one receiving support, but also the ones giving support (Hsiao, Brouns, Kester, \& Sloep, 2009; Roscoe \& Chi, 2007; Wong, Chan, Chou, Heh, \& Tung, 2003). Furthermore, since providing professional support is often too expensive and time-consuming, especially in an online setting, using peers as tutors becomes even more pressing (Kester, et al., 2006). In addition, because the main goal of a LN is to enhance participants' learning, peer-support can have added value for collaborative learning. Collaborative learning refers to peers learning together / from each other in groups of two or more and the benefits gained in this way. Furthermore, collaborative learning can be a stimulus for participants to learn new skills and competencies (B. L. Smith \& MacGregor, 1992).

In this paper we present the theoretical foundations of a peer-support service that aims to foster social capital in Learning Networks communities. In the rest of the paper we will first go into detail with regard to the social capital of a LN. Each pillar is 
explained and conclusions are drawn on what is needed to strengthen these pillars. After that, we introduce the concept of Ad-Hoc Transient Groups (AHTGs). We argue that this concept provides the benefits needed to strengthen the pillars of a LN's social capital. Then, we bring the social capital needs and AHTGs together in a list of hypotheses which will be tested in future experiments. Next, an overview of requirements and a model are given, outlining what we believe is necessary in order to acquire the desired improvements. Finally, an example on how this model will work is given and conclusions are given.

\section{Social Capital}

Social capital represents the relationships among participants of a social network and how these are used to gain benefits (Adler \& Kwon, 2002; Coleman, 1990; Portes, 1998). As argued earlier, to foster social capital in a LN, participants need to be connected, stay in the network by feeling a part of it, and have actions through which benefits are gained. In other words the three pillars of social capital are: the relationship characteristics (Coleman, 1990; Eggens, et al., 2008), the sense of belonging to the community (Hughey, Speer, \& Peterson, 1999; Krebs \& Holley, 2006; Pooley, Cohen, \& Pike, 2005; Rovai, 2002), and the mutual support (Kester et al., 2007).

\section{Relationship characteristics}

The relationship characteristics are an integral part of social capital (Coleman, 1990), they represent how participants are connected to each other as well as how (sub-) communities are interconnected. These relationships allow information to flow through the network and to acquire new or to strengthen existing social contacts 
(Hanneman \& Riddle, 2005). When looking at the relationship characteristics the most important are:

- The number of relationships (Hanneman \& Riddle, 2005)

- The strength of the relationships, within and in between communities (Granovetter, 1973)

- The spread of the relationships (Scott, 2000)

Needless to say, without relationships no contact is achieved. Consequently, the number of relationships is important as it partly defines the general level of communication. However, many relationships per se does not yet mean they are used appropriately (Granovetter, 1973). The strength of these relationships therefore has to be taken into account as well. Strong relationships are those that are used frequently between participants. Strong relationships occur in small tightly-knit groups or communities where participants extensively collaborate and socialize. Additionally, Granovetter (1973) argued that not just strong, but also weak relationships have an important role in social networks. As described above, strong relationships mainly occur in small communities or groups, yet weak relationships especially characterize the contact throughout the social network. These weak relationships are often referred to as bridging relationships. These relationships have the important function to keep participants and communities in contact with other with participants which are not part of the smaller inner groups (Granovetter, 1973; Kavanaugh, Reese, Carroll, \& Rosson, 2003). This allows for fresh ideas to "invade" the smaller community, as well as provide participants with better chances of finding other participants in case of need (Kavanaugh, et al., 2003).

However, knowing the strength of individual relationships still does not say anything about their overall characteristics. One should know how all these 
connections are spread out over the network in order to reveal any bottlenecks. When a small core group of participants is very active, it can make the community prone to becoming unstable (DeSanctis, Fayard, Roach, \& Jiang, 2003; Fetter, Berlanga, \& Sloep, 2008). Because most communication and activity goes through the core participants, the loss of one or more of them could easily disrupt the communication and, as a consequence, information-flow throughout the whole community. Also, participants can become isolated if they are only connected to a core person only, rather than to others as well. A community which depends on a small group of core participants is said to be highly centralized (Scott, 2000). Figure $2 \mathrm{a}$ and figure $2 \mathrm{~b}$ exemplify this. They represent two communities; the first has a high centralization, the second has a low centralization. As can be seen with the first community, most relationships depend solely on a small core group. If one of the core group participants would disappear, a significant number of participants (and groups) is likely to become isolated.

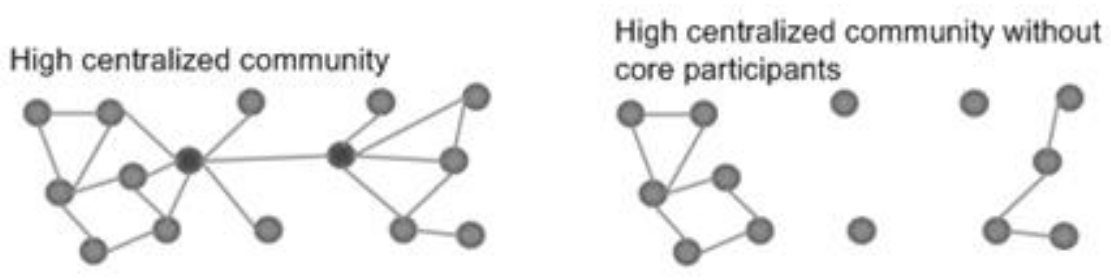

Figure $2 \mathrm{a}$ - high network centralization. Before and after drop-out of central participants.
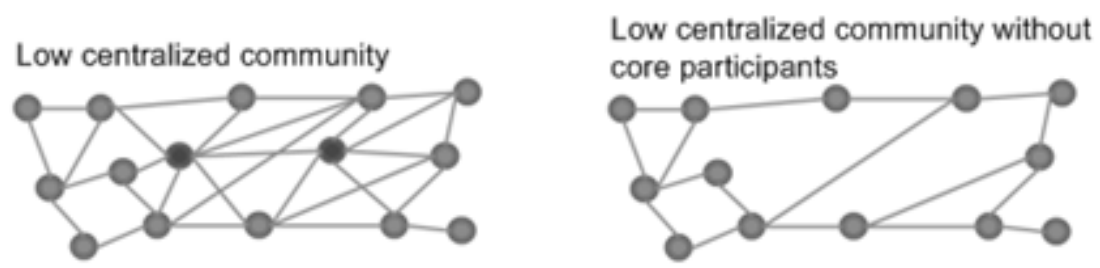

Figure $2 b$ - low network centralization. Before and after drop-out of central participants. 
High centralization brings another problem in its wake. In a highly centralized network core participants are the contact persons for most other participants. This will easily lead to the core participants being flooded with requests. This is problematic because it has been shown that participants are more likely to stop participating if they become overloaded with information (Jones, et al., 2004).

In conclusion for social relationships to have a positive influence on the LN's social capital: (1) there should be many relationships between participants, (2) these should consist of weak and strong links, which (3) should be spread out in a decentralized way.

\section{Sense of belonging to the community}

A sense of belonging or sense of community is another important part of the social capital (Pooley, et al., 2005). Participants need to feel part of the community, feel they have peers they can rely upon (Huang, Brink, \& Groot, 2008) and are able to collaborate with or ask for support (Hughey, et al., 1999; Rovai, 2002). A low sense of belonging can lead to feelings of detachment, isolation, distraction, and lack of personal attention, heightening the chance of participant drop-out (Kester, et al., 2006; McInnerney \& Roberts, 2004; Rovai, 2002). Drop-out is an important problem of online learning communities, as drop-out is often 10 to 20 percent higher than it is for learning communities in which participants meet face to face (Butler, Sproull, Kiesler, \& Kraut, 2001; Poellhuber, Chomienne, \& Karsenti, 2008; Rovai, 2002). Improving a sense of belonging is not only positive for reducing drop-out. It has also been shown to increase the students' involvement in community activities as well as encouraging them to make more contacts (Dawson, 2006; Rovai, 2002). For example, a study done by Dawson (2006) shows there is a significant relationship 
between frequency of communication and sense of belonging. Furthermore, the results support the notion that an increase in communication and sense of belonging improved the community experience of the learners.

Additionally, it has been shown that the existence of a community and a strong sense of belonging can improve participant's retention. Feeling part of a community can be a powerful incentive for learners to stick to their learning goals and see them through, rather than giving up (Rovai, 2002).

We argue that in a LN social capital can be improved by heightening the participants' sense of belonging to the community. Not only through a direct improvement by making them feel part of the community, but also through the indirect effect the sense of belonging to the community should have on reducing drop-out, and the higher incentive for participants to stick to their goals and stay active within the community.

\section{Mutual support}

This aspect of social capital is about actions that foster knowledge sharing within a community. According to Lesser, Fontaine, \& Slusher (2000) these actions positively influence social capital in three ways. First, mutual support becomes an informal type of currency. It allows participants to value each others' performance and willingness to help. Second, combined efforts result in a more positive view on the community as a whole, especially when subjects are closely linked. And finally, to retain social capital, it needs to be maintained, by re-establishing, sustaining, and creating relationships between participants (Adler \& Kwon, 2002; Huang, et al., 2008). 


\section{Ad-Hoc Transient Groups}

In Ad-Hoc Transient Groups (AHTGs) participants work together in a private surrounding to the ad-hoc request after which the group dissipates. In short, participants that have a learning-related request are helped by other participants in a private space ('ad-hoc') and for only a limited amount of time ('transience') (Berlanga, Sloep, Kester, Brouns, \& Koper, 2008; Sloep, 2008). This concept was first introduced as Ad-Hoc Transient Communities (AHTCs), but we have chosen to use the term Ad-Hoc Transient Groups (AHTGs) instead of using the term "community". Our main reasons for this change are the transient and closed aspects of the AHTGs. As summarized by Boomen (2008), a community consists of participants who have ongoing interaction in a shared virtual space. Since AHTGs exist only for a limited time and are only privately accessible, the term "community" is misleading in a way in which the term "group" is not.. The term "group" was chosen following McGrath, Arrow, \& Berdahl (2000) who view groups as 'bounded, structured entities that emerge from the purposive, interdependent actions of individuals'.

It is our goal to deepen the concept of AHTGs so it includes the effects on social capital of a LN. This deepening of the concept is in line with the wish Poole, Hollingshead, McGrath, Moreland, \& Rohrbaugh (2004) bring forward that more interdisciplinary approaches are needed in the field of small-group research. Our starting point is the initial research done by Van Rosmalen et al. (2007), which provides evidence that AHTGs (or AHTCs as they refer to) are appreciated by the participants. In their experiment, participants posted a question, after which two other participants were matched and invited to answer the question. Together the participants worked in a private wiki to answer the question, which was disbanded once the answer had been given. The experiment showed a positive effect on 
learning if peers were selected at random for the AHTG (control group). However, it proved even better to use the matching mechanism (experimental group). Using this mechanism significantly increased the responsiveness, quality of the answers, and perceived usefulness (Van Rosmalen et al., 2008). Based on these initial findings and service design characteristics, we believe the AHTG concept can be extended to the influence on the relationship characteristics and the sense of belonging to the community. In this paper we provide a priori arguments to support the idea that AHTGs do not only improve social capital through better mutual support between participants, but also have a positive influence on the relationship characteristics and the participants' sense of belonging to the community.

As described earlier, it is our main hypothesis that the use of AHTGs will improve social capital. Empirical tests therefore are needed to reveal what influence AHTGs have in a more general sense on the social network structure and on the sense of belonging. In upcoming studies we intend to investigate to what extent AHTGs may function as a lever to decentralize the social network, and increase the sense of belonging (Fetter, et al., 2008). By creating many fleeting moments of contact, an increase and larger spread of ties between learners is expected. This would decrease the centralization and improve the communities' social capital. Furthermore, we expect that by introducing AHTGs the sense of belonging will go up because participants will gain more contacts and feel less isolated as well as perceive the community as more effective because their needs are met. Finally, we also believe that the use of AHTGs will improve the mutual support. Because AHTGs should be easy to use the threshold to do so should be low. This again should lead to 
more requests being made and the participants considering the community to be of higher value.

\section{Requirements}

In order to test the desired effects as stated in the above hypotheses, a LN has to meet several requirements for the tests to be adequate. What follows is an overview of these requirements according to the pillars of social capital mentioned earlier.

\section{Improved relationship characteristics}

To test whether the relationship characteristics improve through decentralizing the community and increasing the relationships between participants, participants with a request should not have to find suitable peers by themselves. If they would have to the workload of the participant would increase extensively, because trying to find the right participant to fulfil a request by oneself might be very difficult. For example, participants might not be aware of the knowledge/competences others have, they do not know all participants in the $\mathrm{LN}$, they will not be so keen on contacting people they do not know, or they might not have the time. Therefore participants need support to find out whom to contact for their request. Because each request is different, so will each advice on which participants should be able to answer the question, and help the participant. In the long run, this means that the number of relationships and their spread will increase, decentralizing the community.

\section{Higher sense of belonging to the community}

To test whether the sense of belonging to the community can be heightened, participants should be able to make contacts, handle requests, and have a high 
chance on meeting again. For this to work, it important that participants are recognizable to each other, as well as have a system for handling requests that is fast and brings participants together. In addition, an increase in perceived community effectiveness is required as it has been shown that an increase in community effectiveness can have a positive influence on the sense of belonging to the community as well (Rovai, 2002). We surmise that to improve the perceived effectiveness, it is important for participants to see what others are doing. To this end, requests made and fulfilled successfully should be publicly accessible (with consent) and there should be enough possibilities for participants to communicate with each other once the AHTG has dissolved.

\section{Better mutual support}

To test increases in mutual support, it is vital that an environment is created in which it pays off to help others. This means that the right cooperation strategy is required. Although many sophisticated strategies have been elaborated, we will, as a first approximation, start off with a tit-for-tat strategy, as described by Axelrod (2006). This collaborative strategy holds that one starts to collaborate as a first move and after that always copies the other person's moves. So collaborating is reciprocated with collaborating and defecting with defecting. This strategy has been shown to be effective under a variety of circumstances (Axelrod, 2006). There are three conditions which are needed for the tit-for-tat strategy. (1) The groups in which participants work together are small, (2) The chance for participants to meet again over time are high, and (3) participants are accountable for their actions. 
These requirements should be considered when defining peer-support services that support AHTG. Figure 3 shows how the social capital pillars, requirements, and services attributes are linked together.

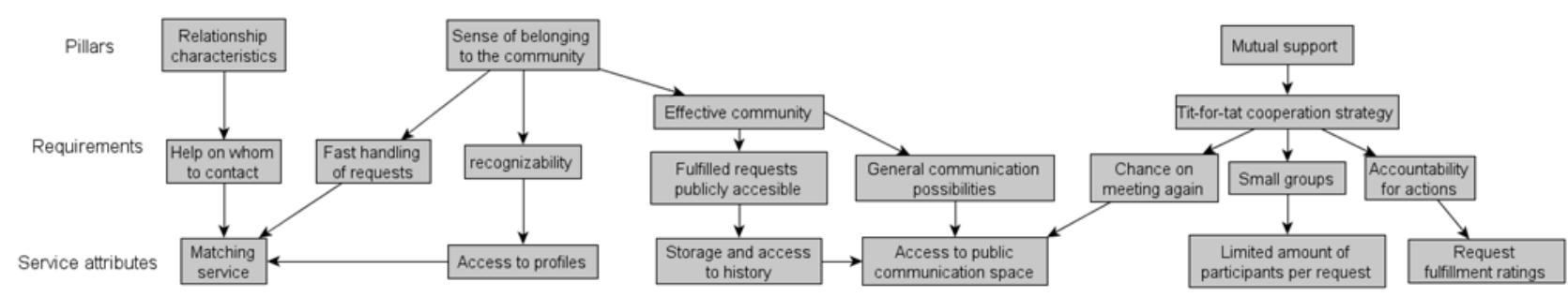

Figure 3 - Social capital pillars, requirements, and service attributes

\section{Ad-Hoc Transient Groups' service attributes}

As argued earlier, it is important for participants to receive advice on whom to contact. To this end, AHTGs will use a peer-matching mechanism. A list of most suitable peers is constructed for each request submitted by a participant. The scores upon which the ranking of most suitable peers is based depends on the data available in the network. For example, an international LN might have a strong need for language matching, whereas the same matching can be without meaning for a $L N$ in which all participants speak the same language. Together the chosen matching scores provide a ranking of the most suitable participants. Following this ranking, participants are personally invited to fulfil the request, and in the case of a rejection the next participant is invited and so on. This loop should also create a fast handling of the request.

For participants to be recognizable, the service will make use of participant profiles. However, because we see AHTGs as being part of a larger online social network (indeed, a LN), it would be preferable if already existing profiles within the LN are used. The same holds for the access to the public history and communication 
space. The AHTG service has to have access to a database service for the history, as well as a general communication method, both used in the LN.

The use of a general communication method together with the AHTGs should lead to a high chance for participants to meet more than once. This combined with a limited number of invited participants per request and request fulfilment ratings should set the stage for a tit-for-tat cooperation strategy to arise. The limited number of participants evidently keeps the groups small and prevents free-riding and spread of responsibility. At the same time the rating of the request fulfilment is expected to have an influence on the accountability of the participants. Clearly these ratings are taken up in participants' profiles and are publicly accessible.

\section{The eTwinning network: an Example}

In order to exemplify how the theoretical foundations of a peer-support service based on the AHTG concept will solve a practical problem, we will briefly describe an existing $L N$ and how the AHTG service will help to foster the social capital of this particular network. The eTwinning network is a network of teachers $(+70.000)$ from all over Europe. Its aim is to provide teachers a platform where they can carry out projects together and learn from each other (eTwinning, 2009). However, at the moment there are many teachers in the network who are not connected to anyone. There are two more issues with the network. Teachers are not able to find the right partner and it is hard to organize collaborative work (eTwinning, 2009). AHTGs can help solve these problems by providing an easy way for teachers to ask questions and thus be brought together. Especially, in large networks like these the matching becomes vital, since manually searching over 70.000 profiles is unmanageable. Using a AHTG peer-support service, teachers can post questions. Once posted, they 
receive a list of best matches and can include / exclude people themselves, and indicate whether they want the system to match them to others. Once appropriate teachers are invited to an AHTG (and have accepted), they work together in a private space where messages can be posted. Once the teacher who asked the question feels the question has been answered satisfactory (or not), she or he closes the question. In closing the question, the questioner indicates whether the answer was satisfactory, and can send the helping teachers a personal message. For a more indepth use-case, see Fetter et al. (2010).

\section{Conclusions}

We believe that using an AHTG peer-support service as outlined above will improve the social capital of the LN. This is done by improving the relationship characteristics, heightening the sense of belonging to the community and intensifying the mutual support between participants. In this paper we presented the theoretical framework and considerations to define an AHTG peer-support service. First steps in this direction have already been made, as reported in Fetter et al. (2009). Using this design, the model will be tested using simulations. These theoretical foundations and upcoming simulations provide the basis for our future experiments that will take place in the European eTwinning network (Fetter, et al., 2010).

\section{References}

Adler, P. S., \& Kwon, S.-W. (2002). Social Capital: Prospects for a New Concept. Academy of Management Review, 27(1), 17-40.

Anderson, B. (2004). Dimensions of learning and support in an online community. Open Learning, 19(2), 183-190.

Arenas, A., Danon, L., Díaz-Guilera, A., Gleiser, P. M., \& Guimerá, R. (2004). Community analysis in social networks. The European Physical Journal B - Condensed Matter and Complex Systems, 38(2), 373-380.

Axelrod, R. (2006). The Evolution of Cooperation - Revised Edition. New York: Basic Books. 
Berlanga, A. J., Sloep, P., Brouns, F., Van Rosmalen, P., Bitter-Rijpkema, M. E., \& Koper, R. (2007). Functionality for learning networks: lessons learned from social web applications. Paper presented at the E-portfolio 2007. Retrieved from http://hdl.handle.net/1820/1011

Berlanga, A. J., Sloep, P., Kester, L., Brouns, F., \& Koper, R. (2008). Ad hoc transient communities: Towards fostering knowledge sharing in learning networks. International Journal of Learning Technology, 3(4), 443-458.

Boomen, M. v. d. (2008). From Community Metaphor to Web 2.0. Paper presented at the IADIS International Conference on Web Based Communities (WEBC 2008), Amsterdam, The Netherlands: IADIS press.

Butler, B., Sproull, L., Kiesler, S., \& Kraut, R. (2001). Community Effort in Online Groups: Who Does the Work and Why. In S. A. L. Weisband (Ed.), Leadership at a Distance (pp. 346-362). Erlbaum.

Chang, B., Cheng, N.-H., Deng, Y.-C., \& Chan, T.-W. (2007). Environmental design for a structured network learning society. Computers \& Education, 48(2), 234-249.

Coleman, J. S. (1990). Foundations of Social Theory: Harvard University Press, UK.

Dawson, S. (2006). A study of the relationship between student communication interaction and sense of community. Internet and Higher Education, 9, 153-162.

Dede, C. (1989). The Evolution of Distance Learning: Technology-Mediated Interactive Learning. Retrieved from http://eric.ed.gov/ERICWebPortal/contentdelivery/servlet/ERICServlet?accno=ED325 $\underline{099}$

DeSanctis, G., Fayard, A.-L., Roach, M., \& Jiang, L. (2003). Learning in Online Forums. European Management Journal, 21(5), 565-577.

Eggens, L., Van der Werf, M. P. C., \& Bosker, R. J. (2008). The influence of personal networks and social support on study attainment of students in university education. Higher Education, 55, 553-573.

eTwinning. (2009). Monitoring of the eTwinning programme: Results of a survey in 29 European countries. Retrieved from http://www.etwinning.net

Fetter, S., Berlanga, A. J., \& Sloep, P. B. (2008). Strengthening the Community in Order to Enhance Learning. Paper presented at the Doctoral Consortium at the IADIS International Conference on Web Based Communities (WEBC 2008), Amsterdam, The Netherlands: IADIS press.

Fetter, S., Berlanga, A. J., \& Sloep, P. B. (2009). Designing an Ad Hoc Transient Communities Service in Order to Enhance the Social Capital of Learning Communities. In M. Spaniol, Q. Li, R. Klamma \& R. W. H. Lau (Eds.), 8th International Conference on Web-based Learning (ICWL) (pp. 150-157). Aachen, Germany: Springer.

Fetter, S., Berlanga, A. J., \& Sloep, P. B. (2010). Using Ad Hoc Transient Communities to Strengthen Social Capital: Design Considerations. Paper presented at the 7th International Conference on Networked Learning, Aalborg, Denmark.

Granovetter, M. S. (1973). The Strength of Weak Ties. American Journal of Sociology, 78(6), 1360-1380.

Hanneman, R. A., \& Riddle, M. (2005). Introduction to social network methods: Riverside, CA: University of California, Riverside (published in digital form at http://faculty.ucr.edu/ hanneman/).

Hsiao, Y. P., Brouns, F., Kester, L., \& Sloep, P. B. (2009, November, 20-22, 2009). Optimizing Knowledge Sharing In Learning Networks Through Peer Tutoring. Paper presented at the IADIS International Conference Cognition and Exploratory Learning in Digital Age (CELDA 2009), Rome, Italy: Springer. 
Huang, J., Brink, H. M. v. d., \& Groot, W. (2008). A meta-analysis of the effect of education on social capital. Economics of Education Review, In Press, Accepted Manuscript.

Hughey, J., Speer, P. W., \& Peterson, N. A. (1999). Sense of community in community organizations: Structure and evidence of validity. Journal of Community Psychology, 27(1), 97-113.

Johnson, C. (2001). A survey of current research on online communities of practice. Internet and Higher Education, 4, 45-60.

Jones, Q., Ravid, G., \& Rafaeli, S. (2004). Information Overload and the Message Dynamics of Online Interaction Spaces: A Theoretical Model and Empirical Exploration. Information Systems Research, 15(2), 194-210.

Kadushin, C. (2004). Too Much Investment in Social Capital? Social Networks, 26, 75-90.

Kavanaugh, A., Reese, D. D., Carroll, J. M., \& Rosson, M. B. (2003). Weak Ties in Networked Communities. Paper presented at the First International Conference on Communities and Technologies, C\&T 2003, Amsterdam, The Netherlands.

Kester, L., Sloep, P. B., Van Rosmalen, P., Brouns, F., Koné, M., \& Koper, R. (2007). Facilitating community building in Learning Networks through peer tutoring in ad hoc transient communities. International Journal on Webbased Communities, 3(2), 198205.

Kester, L., Van Rosmalen, P., Sloep, P., Brouns, F., Brouwers, M., \& Koper, R. (2006). Matchmaking in Learning Networks: A System to Support Knowledge Sharing. Paper presented at the International Workshop in Learning Networks for Lifelong Competence Development, March, 30-31, 2006, Sofia, Bulgaria: TENCompetence Conf.

Koper, R., Rusman, E., \& Sloep, P. (2005). Effective Learning Networks. Lifelong learning in Europe, 1, 18-27.

Krebs, V., \& Holley, J. (2006). Building Smart Communities through Network Weaving. Retrieved from http://www.orgnet.com/BuildingNetworks.pdf

Lesser, E. L., Fontaine, M. A., \& Slusher, J. A. (2000). Communities of Practice, Social Capital and Organizational Knowledge Knowledge and Communities (pp. 123-132): Butterworth-Heinemann.

Lock, J. V. (2002). Laying the groundwork for the development of learning communities within online courses. The Quarterly Review of Distance Education, 3(4), 395-408.

McGrath, J. E., Arrow, H., \& Berdahl, J. L. (2000). The Study of Groups: Past, Present, and Future. Personality \& Social Psychology Review (Lawrence Erlbaum Associates), 4(1), 95-105.

McInnerney, J. M., \& Roberts, T. S. (2004). Online Learning: Social Interaction and the Creation of a Sense of Community. Educational Technology \& Society, 7(3), 73-81.

Norris, H., Stevens, S., Pfefferbaum, B., Wyche, K., \& Pfefferbaum, R. (2007). Community Resilience as a Metaphor, Theory, Set of Capacities, and Strategy for Disaster Readiness. American Journal of Community Psychology, 41(1-2), 127-150.

Poellhuber, B., Chomienne, M., \& Karsenti, T. (2008). The Effect of Peer Collaboration and Collaborative Learning on Self-Efficacy and Persistence in a Learner-Paced Continuous Intake Model. Journal of Distance Education, 22(3), 41-62.

Poole, M. S., Hollingshead, A. B., McGrath, J. E., Moreland, R. L., \& Rohrbaugh, J. (2004). Interdisciplinary Perspectives on Small Groups. Small Group Research, 35(1), 3-16.

Pooley, J. A., Cohen, L., \& Pike, L. T. (2005). Can sense of community inform social capital? The Social Science Journal, 42, 71-79.

Portes, A. (1998). Social Capital: Its Origins and Applications in Modern Sociology. Annual Review of Sociology, 24(1), 1. 
Roscoe, R. D., \& Chi, M. T. H. (2007). Understanding Tutor Learning: Knowledge-Building and Knowledge-Telling in Peer Tutors' Explanations and Questions. Review of Educational Research, 77(4), 534-574.

Rovai, A. P. (2002). Building Sense of Community at a Distance. International Review of Research in Open and Distance Learning, 3(1), 1-12.

Scott, J. (2000). Social Network Analysis: A Handbook. (2nd ed.). London: SAGE.

Sloep, P. B. (2008). Building a Learning Network through Ad-Hoc Transient Communities. Paper presented at the ICCMSN, Dunedin, New Zealand.

Smith, A., \& Kollock, P. (1999). Communities in Cyberspace. London: Routledge.

Smith, B. L., \& MacGregor, J. T. (1992). What is Collaborative Learning? In A. S. Goodsell, M. Maher, V. Tinto, B. L. Smith \& J. T. MacGregor (Eds.), Collaborative Learning: A Sourcebook for Higher Education. (pp. 10-30): National Center on Postsecondary Teaching, Learning, and Assessment (NCTLA).

Van Rosmalen, P., Sloep, P., Kester, L., Brouns, F., de Croock, M., Pannekeet, K., et al. (2008). A learner support model based on peer tutor selection. Journal of Computer Assisted Learning, 24(1), 74-86.

Wenger, E. (2004). Knowledge management as a doughnut: Shaping your knowledge strategy through communities of practice. Ivey Business Journal, January/February, 1-8.

Wong, W. K., Chan, T. W., Chou, C. Y., Heh, J. S., \& Tung, S. H. (2003). Reciprocal tutoring using cognitive tools. Journal of Computer Assisted Learning, 19, 416-428. 